\title{
A SURVEY OF QUALITY OF USING FRYING OILS IN SOME FAST FOODS RESTAURANTS \\ Rabie, M. M. ${ }^{1}$; Rania E. El-gammal ${ }^{1}$ and A. A. El-sayed ${ }^{2}$ \\ 1- Food Industries Dept., Fac.of Agric., Mansoura university. \\ 2- Hotel Studies Dept.,Fac.of Hotels and Tourism, Mansoura university.
}

\begin{abstract}
Frying oils were evaluated into two methods .Firstly the chemical evaluation, by determining some physico- chemical characteristics namely specific gravity (SG), acid value (AV), Peroxide value (PV), free fatty acids (FFA\%) and fatty acids profile and results indicated that acid value of frying oils samples were 1.34 before frying and reached to 8.36 after frying process in high grade restaurant ,while the Peroxide value being 22.435 before frying but after frying reached $417.39 \mathrm{ml}$ eqv./kg oil Also, frying process showed a high percentage of harmful trans fatty acids in all fried oil sample.

Secondly the survey study consists of two parts, the first part is concerned with the staff who work in fast food restaurants and the second part is concerned with the guests who usually eat some fast foods meals .

Results showed that the age of the staff who worked in fast food restaurants which answered to Less than25 years ,25 to 35 years and36 - 45 more and It's obvious that the gender was male with $100 \%$ and the age was between 25-35 with $48.6 \%$ and $36-45$ and more with $50 \%$., the reasons of using the most common frying oils in this question which answered to price, oil smell, flavor and other reasons.

We have found also, that the gender of the people who eat fried products more than the other are equal with $46 \%$ for males and $46 \%$ for females .and the age of the customers who eat in fast food restaurants which answered to $45.7 \%$ were from 20 to 30 years and 30 to 40 and more with $37 \%$.

Then we have to know if there is stability in the taste of fried product that the customers eat in the restaurant and the result was $42.4 \%$ with yes and $26.1 \%$ with no and $31.5 \%$ with sometimes.

Finally, we have to know what are the flaws that the customers have seen before in fried food from their point of view and we have found the biggest flaw was changing the taste with $52.2 \%$ then changing the color with $31.5 \%$ then $16.3 \%$ was for the changing of the smell.

So, it's clear from the results of previous tests and questionnaires we need to focus on the process of frying and Oil Change to avoid the formation of harmful compounds health operations especially trans fatty acids and saturated fatty acids.

This research aimed to study and evaluate the quality of some frying oils which were randomly collected from some fast food restaurants three categories ( international, national and local ) in El-Dakahlia Governorate.
\end{abstract}

\section{INTRODUCTION}

The National Restaurant Association (N R A) defines the fast food industry as " encompassing all meals and snacks prepared outside the home and this definition therefore includes all takeout meals and beverages. It's also known as a quick service restaurant (QSR) within the industry, is a specific type of restaurant characterized both by its fast food cuisine and by minimal table service. Food served in fast food restaurants typically caters to 
a "meat-sweet diet" and is offered from a limited menu; is cooked in bulk in advance and kept hot (Talwar ,2003)

Restaurants have been around in some form for most of human civilization. McDonalds, burger king, Taco bell, Hardees and Kentucky are the most famous fast food restaurants in the world, (Talwar, 2003 and Anon.,2000).

Food frying has long been used as a technique to prepare various foods both at home and in industrial food sectors since fried foods developed a much desired texture, flavor and appearance they are consumed in large quantities all over the world . the popularity of fast food is due to the surface texture , crunchiness and flavor. Especially the fast food sector uses frying widely.(Anon.,2000).

Frying oils is a common and popular method of preparing foods because its fast, simple, develops typical flavor of foodstuffs and is very efficient from a culinary point of view . During deep frying oils are repeatedly and often over long Periods of time exposed to temperatures between $130^{\circ}$ $\mathrm{C}$ and $200^{\circ} \mathrm{C}$ in the presence of the food that is being fried and in the presence of air and water the properties of frying oil have a principal effect on the quality of deep fried foods and degradation products that accumulate in frying baths worsen technical properties of the oil and spoil the food they also have a negative effect on human health effect on viscosity color and dielectric capacitance and chemical markers namely fatty acids FFA , anisidine values total polar compounds(TPC), peroxide value and others number of countries food related legislation includes practical instructions and agreed parameters specifying the overall content of degradation products which helps to monitor oil quality during frying the values of 2,5 for fatty free acids 10 for polymer triacyiglycerides of all lipids and 25 for total polar compounds are considered to be the upper limits 5 , (Cizkovaet al 2 ., 2011).

\section{The objectives of the study:}

This study was aimed to evaluate fried oil quality in some fast food restaurants in EL -Dakahlia Governorate.

in order to achieve these aims :

1- Collect six samples of frying oil used in some fast food restaurants which are situated in EL- Dakahlia Governorate .

2- Determination of some physical and chemical properties of fried oils namely acid value (AV), peroxide value (PV) , smoke point , specific gravity and the FFA free fatty acids.

3- Survey Statically analysis of the questionnaires (for the staff and the customers).

\section{MATERIALS AND METHODS}

Materials :

\section{Collection of oil samples:}

Total of 6 frying oil samples were collected twice a month from three categories ( high, medium and local)fast food restaurants in El-Dakahlia Governorate, El-mansoura ,Egypt . during October 2013. 


\section{Study design:}

Around $500 \mathrm{ml}$ of fried oil samples collected from Bilqas city and Mansoura city were taken directly from the fryer in-use which contained a removable desk to filtrate the oil ,collected oil were kept an amber colored capped glass and labeled, until the analyses.

\section{Chemicals :}

All chemicals were purchased from El-Gomhouria pharmaceutical and chemist company , EL-Mansoura city, El Dakahlia Governorate , Egypt.

Methods:

\section{Physical properties:}

Specific gravity, smoke point were determined according to the method described by (A.O.A.C. 2000).

\section{Chemical properties:}

Acid value(Av), free fatty acids (FFA)\% and Peroxide value (PV) were determined according to AO.AC(2000).

Fatty acids composition : fatty acids methyl esters (FAMs ) of oils were performed according (Radwan1978),.At Higher Health Institution ,Alexandria university, Egypt .

Questionnaires :

We have performed two types of questionnaires to compare the measured physical and chemical parameters and surveys together. These questionnaires were evaluated by specified staff members in faculty of tourism and hotels in Mansoura and Helwan universities. The first type of questionnaires has been performed for the staff of the restaurants to compare their answers with the chemical and physical results. And the second one is been performed on the guests to evaluate their answers and measuring the quality of the fried products. This statically evaluation has used the Spss program to perform this analysis.

\section{Statically analysis:}

All obtained results in the questionnaires were statistically analyses using Spss program version (20).

\section{Quantitative Assessment of Frying Oil Quality...}

The Questionnaire used for Assessment of Frying oils used in Fast Food Restaurants.

This questionnaire aims to control and evaluate all frying oils in fast food restaurants and know the best types of these oils.

Name of the restaurant (if he want ):

\section{Personal information :}

\section{Personal data}

Gender:

o Male.

- Female.

Age:

- Less than25 years.

o 25 to 35 years.

- $36-45$ (more).

position :

Date of the survey: / / 2014 
Q1) which type of oil are you using for frying in your restaurant?

\begin{tabular}{|l|l|l|}
\hline Type of oil & & \\
\hline a) Sunflower oil (SFO) & & \\
\hline b) Corn oil (CNO) & & \\
\hline c) Palm oil (plo) & & \\
\hline d) mixed oils & & \\
\hline e) Shortening & & \\
\hline f) other oil & & \\
\hline
\end{tabular}

Q2) What is the reason for using this oil?

\begin{tabular}{|l|l|}
\hline a) Price & \\
\hline b) oil smell & \\
\hline c) Flavor (fla) & \\
\hline d) Other reasons (otr) & \\
\hline
\end{tabular}

Q3) How many hours a day do you perform frying?
a) 4-6 hours
c) 8-10 hours
b) 6-8 hours
e) 12-14 hours
d) 10-12 hours

Q4) After the end of a day, how do you utilize the remaining oil next day?
a) Add materials for oil to prolong the period of use.
b) putting it away and using new one .
c) other ways .

Q5) How often do you change your oil?
a) Every day
c) Every week
b) Every two days.
d) other duration

Q6) What do you do with your waste frying oils?
a) Pour into the wastewater pipe
b) Collect and dispose it into trash
c) Collect and sell to a buyer
d) Other usage

Q7) How do you clean your fryer?
a) Hot water and soap
b) Spray cleaner

c) Other way

Q8) Do you perform any treatment to extend the usage life of your frying oil?
a) yes
b) no

Q9) Do you have any knowledge about Food Codex regulations for frying oils?
a) yes
b) no

10) What are the problems that you face in general in the stages of your use of frying oils in the restaurant?
a) High prices
c) Lack of stability of oils used in frying process.
b) product quality
D) other problems

Quantitative Assessment of Frying Oil Quality...

The Questionnaire Used for Assessment of Frying in Fast Food Restaurants.

This questionnaire aims to control and evaluate all the frying oils in fast food restaurants and know the best types of these oils.. 
Name of the restaurant ( if he want ):

Personal information :

1. Personal data

Gender:

o Male. $\quad$ o Female.

Age: $\quad$ L Less than10 years.

30 to 40 (more). 0

Job :

Date of the survey: / / 2014

Q1) do you always eat fried foods?
a)yes
b) no
c) sometimes

Q2) Is there stability in the taste of the fried product you eat here in the restaurant?
a)yes
b) no
c) sometimes

Q3) Is there stability in the color of the fried product you eat here in the restaurant?
a) yes
b) no
c) sometimes

Q4) for your point of view, does the number of hours of frying affect on the quality of the fried product?
a) yes
b) no
c) don't know

Q5) in the case of knowing that the frying oil is being reused many times, would u have the meal ?
a) yes
b) no

Q6) what are the flaws that you have ever seen before in the fried foods ?
a) Changing of the color
b) Changing of the taste
c) Changing of the smell
d) Other flaws

\section{RESULTS AND DISCUSSION}

-Changes in physico-chemical characteristics in some fried oil samples collected from fast food restaurants before and after frying process:

All collected fried oil samples were physically and chemically evaluated before and after frying using some characteristics namely smoke point ,specific gravity, acid value(AV), peroxide value(PV) and Free Fatty acids (FFA\%) and all obtained results were tabulated in Table (1) :

\begin{tabular}{|l|c|c|c|c|c|c|}
\hline \multirow{2}{*}{ Oil Samples } & \multicolumn{3}{|c|}{$\begin{array}{c}\text { Before frying process } \\
\text { (zero time ) }\end{array}$} & \multicolumn{3}{c|}{$\begin{array}{c}\text { After frying process } \\
(\mathbf{1 2 - 1 4} \text { hours ) }\end{array}$} \\
\cline { 2 - 7 } PROPERTIES & $\mathbf{1}$ & $\mathbf{2}$ & $\mathbf{3}$ & $\mathbf{4}$ & $\mathbf{5}$ & $\mathbf{6}$ \\
\hline Smoke point & $160^{\circ} \mathrm{C} /$ & $160^{\circ} \mathrm{C} /$ & $120^{\circ} \mathrm{C} /$ & $130 \mathrm{C} /$ & $180 \mathrm{C} /$ & $110 \mathrm{C} /$ \\
& $11 \mathrm{~min}$. & $10.07 \mathrm{~min}$ & $9.00 \mathrm{~min}$. & $7.5 \mathrm{~min}$. & $7.23 \mathrm{~min}$ & $7.45 \mathrm{~min}$. \\
\hline Specific gravity & 0.7947 & 0.7065 & 0.6476988 & 0.9124 & 0.8829 & 0.8241694 \\
\hline A.V & 0.60 & 1.34 & 0.64 & 2.40 & 8.63 & 2.13 \\
\hline P.V & 78.57 & 22.435 & 96 & 275 & 217.39 & 226.53 \\
\hline FFA\% & 2.215 & 6.326 & 2.707 & 7.755 & 11.770 & 6.388 \\
\hline
\end{tabular}

$1,4:$ fried oil samples from national grade restaurant.

2,5: fried oil samples from international grade restaurant.

3,6 : fried oil samples from local grade restaurant . 
Acid value was used to asses frying oil degradation and it is related to fried food Quality. Also Acid value (AV) was used to measure the formation of acidic compounds in oil during hydrolysisin process(Iqbal et al.,2008).

Data presented in Table (1) indicated that acid values were $0.60,1.34$ and $0.64 \mathrm{mgKOH} / \mathrm{g}$.Oil in different fried oil samples 1,2,3 before frying and reached to $2.40,8.63$ and 2.13 after frying in the same samples respectively , the highest value of A.V was $1.34 \mathrm{mg} \mathrm{KOH} / \mathrm{g}$. oil in oil sample collected from high grade restaurant before frying and reached to $8.63 \mathrm{mg} \mathrm{koh} / \mathrm{g}$. after frying these results of acid values after frying may be due to the condition of frying process.

Also being results in the same Table showed the changes in F.F.A\% $2.215 \%, 6.326 \%, 2.707 \%, 7.755 \%, 11.770 \%$ and $6.388 \%$ respectively in fried oil samples before and after frying process .

While the changes in FFA\%. In high, medium and local grade fast food restaurants could be attributed to high temperature up to $185^{\circ} \mathrm{C}$ which caused the deterioration and hydrolysis of fatty acids (Chen et al., 2013).

\section{Changes in peroxide values $\left(\mathrm{PV}_{\mathrm{S}}\right)$ :}

Peroxide values was used an index for the degree of Lipid oxidation and the formation of Hydro peroxides as primary oxidation products (Chavan, 1992). Results in Table (1) also, showed the changes in peroxide values in different frying oils collected from fast food categories restaurants .

Data presented in Table (1) showed that the peroxide values for frying oil in international grade fast food restaurants presented 22.435 and $\mathrm{mL}$ eqv. $\mathrm{kg}$ oil respectively before frying there were an observed increase in all oil sample after frying reached to $217.39 \mathrm{~mL}$ eqv./Kg oiL.

Also, the same trend of increase was also observed in all frying oil samples which collected from national grade fast food restaurants the values of peroxide being 78.57 before frying and reached to $275 \mathrm{ml}$ eqv. $/ \mathrm{kg}$ oil after frying.

Also, data illustrated in Table (1) proved that the peroxide values in all frying oil samples from local grade restaurants were 96 before frying and reached to $226.53 \mathrm{~mL}$ eqv. $/ \mathrm{kg}$ oil after frying.

These increments in $\mathrm{PV}_{S}$ could be attributed to the formation of hydro peroxides (primary oxidation products) and the direct effect of heat which enhance the oxidation and rancidity process and the presence of air and water during frying treatments which effect on oil degradation .

\section{Changes on fatty acids profile of frying oils used in some food restaurants.}

Changes in fatty acids composition in high temperature specially frying had a negative effect on fatty acids composition in addition oil fatty acids composition is an initial indicator on its nutritional value, it will fact that the increasing of saturated fatty acids in the diet will increase the level of blood cholesterol which related to the direct effect on coronary heart diseases . ( Chowdhury et al.,(2007).

Results in tables 2,3 and 4 showed the changes on fatty acids profile of different fried oil samples collected from three categories fast food restaurants. 
Table (2): Changes on fatty acids profile of frying oils collected from international grade fast food restaurants before and after frying process:

\begin{tabular}{|c|c|c|}
\hline Fatty acids & \multirow{2}{*}{ Before } & \multirow{2}{*}{ After } \\
\hline Saturated fatty acids & & \\
\hline Caprylic acid (C8:0) & 0.099 & 0.305 \\
\hline Lauric acid (C12:0) & 0.527 & 1.003 \\
\hline Tridecylic acid (C13:0) & 0.765 & 1.319 \\
\hline Myristic acid (C14:0) & 3.887 & 10.782 \\
\hline Pentadecylic acid (C15:0) & 0.604 & 1.725 \\
\hline Palmitic acid (C16:0) & 0.016 & 0.037 \\
\hline Margaric acid (C17:0) & 0.289 & 0.793 \\
\hline Stearic acid (C18:0) & 22.899 & 59.556 \\
\hline Arachidic acid (C20:0) & 1.344 & 1.726 \\
\hline Heneicoylic acid (C21:0) & 0.952 & ND \\
\hline Total saturated fatty acid & 31.382 & 77.246 \\
\hline \multicolumn{3}{|l|}{ Unsaturated fatty acids } \\
\hline Myristoleic acid (C14:1) & 0.988 & 1.125 \\
\hline Ginkgolic acid (C15:1) & 0.530 & 0.778 \\
\hline Palmitoleic acid (C 16:1) & 0.321 & 18.519 \\
\hline Oleic acid (C18:1) & 66.059 & 0.025 \\
\hline Linoleic acid (C18:2) & 0.010 & 0.022 \\
\hline Eicosadienoic acid (C20:2) & 0.335 & 1.994 \\
\hline Erussic acid (C 22:1) & 0.366 & ND \\
\hline Brassic acid (C22:2) & 0.266 & ND \\
\hline Total unsaturated fatty acid & 68.509 & 22.463 \\
\hline Total fatty acids \% & 99.891 & 99.709 \\
\hline
\end{tabular}

Data in Table (2) showed the changes in total saturated fatty acids being 31.382 to (77.246) for frying oil which collected from international grade restaurant and the predominant fatty acids being stearic acid (C18:0) followed by Myristic acid (C14:0) being 22.899 and 59.556 and 3.887 and 10.782 respectively in oil before and after frying process.

From the same results in Table ( 2) it could be observed that the changes in unsaturated fatty acid (USFA) being 68.509 and 22.463 these were an observed decrease in the total of USEA after frying these observed changes could be due to the saturation phenomenon which occurred during frying process and converted the unsaturated bonds to saturated bonds in fatty acids.

Concerning to the results in the same Table it could be observed that the concentration of oleic acid (C18:1) was progressively changed from 66.059 to 0.025 before and after frying process.

From the same table also it could be observed that the main unsaturated fatty acid were oleic acid represented before and after frying process.

Finally the changes in fatty acid compositions in frying oil used from national grade fast food restaurants ,Data illustrated that the fatty acids identified in oil before and after frying process at $180^{\circ} \mathrm{C}$ for 12 hours. 
Table(3) Changes on fatty acids profile of frying oils collected from local grade fast food restaurant:

\begin{tabular}{|l|c|c|}
\hline Fatty acids & Before & After \\
\cline { 1 - 2 } a) Saturated fatty acids: & 0.096 & 0.093 \\
\hline Caprylic acids (C8:0) & 0.229 & ND \\
\hline Undecylic acidC11:0 & 0.112 & 0.117 \\
\hline Lauric acid (C12:0) & 0.582 & 0.266 \\
\hline Tridecylic acid (C13:0) & 0.970 & 0.479 \\
\hline Myristic acid (C14:0) & 0.331 & 0.160 \\
\hline Pentadecylic acid (C15:0) & 22.965 & 3.261 \\
\hline Palmitic acid (C16:0) & 0.126 & 1.129 \\
\hline Margaric acid (C17:0) & 12.113 & 57.261 \\
\hline Stearic acid (C18:0) & 0.528 & 0.457 \\
\hline Arachidic acid (C20:0) & 0.293 & ND \\
\hline Heneicoylic acid (C21:0) & 38.345 & 63.223 \\
\hline Total saturated fatty acid & & \\
\hline b) Unsaturated fatty acids: & 0.214 & 0.425 \\
\hline Myristoleic acid (C14:1) & 0.419 & 0.221 \\
\hline Ginkgolic acid (C15:1) & 0.137 & 6.235 \\
\hline Palmitoleic acid (C 16:1) & 0.109 & 0.095 \\
\hline Heptadecenoic acid (C17:1) & 24.609 & 13.862 \\
\hline Oleic acid (C18:1) & 8.550 & 7.381 \\
\hline Linoleic acid (C18:2) & 0.390 & 0.677 \\
\hline Eicosadienoic acid (C20:2) & 0.824 & 0.159 \\
\hline Erussic acid (C22:1) & 0.602 & 0.522 \\
\hline Brassic acid (C22:2) & 35.859 & 29.577 \\
\hline Total unsaturated fatty acids & & \\
\hline
\end{tabular}

Table(4) Changes on fatty acids profile of frying oils collected from in national fast food restaurants.

\begin{tabular}{|l|c|c|}
\hline Fatty acids & Before & After \\
\hline Saturated fatty acids & & 4.85 \\
\hline Myristic acid (C14:0) & 4.581 & 29.59 \\
\hline Stearic acid (C18:0) & 24.124 & 1.91 \\
\hline Arachidic acid (C20:0) & $\mathrm{ND}$ & 1.46 \\
\hline Heneicoylic acid(C21:0) & 0.696 & 37.81 \\
\hline Total saturated fatty acid & 29.401 & 3.025 \\
\hline Unsaturated fatty acids & & 15.28 \\
\hline Myristoleic acid (C14:1) & 0.238 & 36.61 \\
\hline Oleic acid (C18:1) & 64.957 & 7.37 \\
\hline Elaidic acid (C18:1 t) & $\mathrm{ND}$ & 0.44 \\
\hline Linoelaidic acid (C18:2 t) & $\mathrm{ND}$ & 62.725 \\
\hline Eicosadienoic acid (C20:2) & 4.540 & 100.535 \\
\hline Total unsaturated fatty acid & 69.735 & \\
\hline Total fatty acids & 99.136 & \\
\hline
\end{tabular}

ND: Not detected 
The total saturated and unsaturated fatty acids constitute about 69.735 and 62.725 respectively. The main saturated fatty acids were myristic acid and stearic acid being $4.581,4.850,24.124$ and 29.59 before and after frying.

From table (4) it could be observed that the main unsaturated fatty acid was oleic acid being 64.957 before frying and 15.289 after frying .

Table (5) Trans fatty acids of frying oil samples collected from fast food restaurants after frying process 14 hours:

\begin{tabular}{|l|c|c|c|c|}
\hline \multicolumn{2}{|c|}{ Fatty acids } & \multicolumn{3}{c|}{ oil samples } \\
\cline { 2 - 5 } & Oleic C18:1 & A & B & C \\
\hline $\begin{array}{l}\text { Zero } \\
\text { (before } \\
\text { frying) }\end{array}$ & Lenoleic C18:2 & 0.01 & 24.609 & 64.95 \\
\hline \multirow{4}{*}{ After frying } & Oleic C18:1 & 0.025 & 13.862 & 15.28 \\
\cline { 2 - 5 } & Linoleic C18:2 & 0.022 & 7.381 & 0.019 \\
\cline { 2 - 5 } & Eliadic C18:1t & 31.455 & 30.455 & 36.619 \\
\cline { 2 - 5 } & LinoelaidicC18:2t & 7.793 & 7.763 & 7.379 \\
\hline
\end{tabular}

$A=$ oil sample from international grade restaurant

$B=$ oil sample from local grade restaurant

C = oil sample from national grade restaurant

Trans fatty acids are types of unsaturated fatty acids which are uncommon in nature but can be created artificially. They appear during hydrogenation process also during exposure oil to high temperature especially frying process. The formation of trans fatty acids during frying is closely related to the process temperature and oil use time. When partially hydrogenated oils are used, the formation of trans fatty acids is generally lower (Martin et al., 2007).

The adverse effect of excess intake of trans fatty acids on human health, mainly on cardiovascular system is a growing fatty acids on human health, mainly on cardiovascular system is a growing significant changes in the quality of trans fat while giving the heat treatment.

Data in Table (5) showed different types of trans fatty acids which appeared in frying oils sample. Results mentioned that there were two types only were presented in two blends were oleic acid(C 18:1) and eliadic acid(C 18:1t )Results indicated that there was an observed decrease in oleic acid after frying in all three fried oil samples. The oils were in the legal limit of trans fatty acids had ranged from $(0.11: 11 \mathrm{gm} / 100 \mathrm{gm}$ (Podmore, 2008).So obtained results indicated that all trans fatty acids were progressively increase to 36.619 and $7.793 \mathrm{gm} / 100 \mathrm{gm}$ for Eliadic (c18:1t) and Linoelaidic (C18:2t) respectively, these results may be due the use of high temperature during frying process which formation trans fatty acids due to the isomerization process . 
Rabie, M. M. et al.

** second part of evaluation :

Table (6) Statistical results of questionnaire which has been performed for the staff of the restaurants

\begin{tabular}{|c|c|c|c|}
\hline Question number & Selections & Frequency & Percent \\
\hline Q1 & $\begin{array}{l}a \\
b\end{array}$ & $\begin{array}{c}70 \\
0\end{array}$ & $\begin{array}{c}100 \% \\
0 \%\end{array}$ \\
\hline Q2 & $\begin{array}{l}\mathrm{a} \\
\mathrm{b} \\
\mathrm{c}\end{array}$ & $\begin{array}{c}1 \\
34 \\
35\end{array}$ & $\begin{array}{c}1.4 \% \\
48.6 \% \\
50 \%\end{array}$ \\
\hline Q3 & $\begin{array}{l}a \\
b \\
c \\
d \\
e \\
f\end{array}$ & $\begin{array}{c}7 \\
2 \\
0 \\
7 \\
54 \\
0 \\
\end{array}$ & $\begin{array}{c}10 \% \\
2.9 \% \\
0 \% \\
10 \% \\
77.1 \% \\
0 \% \\
\end{array}$ \\
\hline Q4 & $\begin{array}{l}a \\
b \\
c \\
d\end{array}$ & $\begin{array}{c}47 \\
4 \\
18 \\
1 \\
\end{array}$ & $\begin{array}{c}67.1 \% \\
5.7 \% \\
25.7 \% \\
1.4 \%\end{array}$ \\
\hline Q5 & $\begin{array}{l}a \\
b \\
c \\
d \\
e \\
f\end{array}$ & $\begin{array}{c}0 \\
1 \\
8 \\
30 \\
31 \\
0\end{array}$ & $\begin{array}{c}0 \% \\
1.4 \% \\
11.4 \% \\
42.9 \% \\
44.3 \% \\
0 \%\end{array}$ \\
\hline Q6 & $\begin{array}{l}a \\
b \\
c\end{array}$ & $\begin{array}{c}5 \\
63 \\
2 \\
\end{array}$ & $\begin{array}{l}7.1 \% \\
90 \% \\
2.9 \% \\
\end{array}$ \\
\hline Q7 & $\begin{array}{l}a \\
b \\
c \\
d\end{array}$ & $\begin{array}{c}53 \\
12 \\
5 \\
0 \\
\end{array}$ & $\begin{array}{c}75.7 \% \\
17.1 \% \\
7.1 \% \\
0 \% \\
\end{array}$ \\
\hline Q8 & $\begin{array}{l}a \\
b \\
c \\
d\end{array}$ & $\begin{array}{c}11 \\
14 \\
45 \\
0\end{array}$ & $\begin{array}{c}15.7 \% \\
20 \% \\
64.3 \% \\
0 \%\end{array}$ \\
\hline Q9 & $\begin{array}{l}a \\
b \\
c\end{array}$ & $\begin{array}{c}53 \\
15 \\
2 \\
\end{array}$ & $\begin{array}{c}75.7 \% \\
21.4 \% \\
2.9 \% \\
\end{array}$ \\
\hline Q10 & $\begin{array}{l}a \\
b\end{array}$ & $\begin{array}{l}16 \\
54\end{array}$ & $\begin{array}{l}22.9 \% \\
77.1 \%\end{array}$ \\
\hline Q11 & $\begin{array}{l}a \\
b\end{array}$ & $\begin{array}{c}9 \\
61 \\
\end{array}$ & $\begin{array}{l}12.9 \% \\
87.1 \% \\
\end{array}$ \\
\hline Q12 & $\begin{array}{l}a \\
b \\
c \\
d\end{array}$ & $\begin{array}{c}49 \\
6 \\
15 \\
0\end{array}$ & $\begin{array}{c}70 \% \\
8.6 \% \\
21.4 \% \\
0 \%\end{array}$ \\
\hline
\end{tabular}

A questionnaire composed of 12 questions has been applied to 70 restaurants and their responses (\%) for each selection. It's clear that in 
question (1) asks about the age of the staff who work in fast food restaurants which answered to Less than 25 years, 25 to 35 years and36 - 45 more.

It's obvious that the gender was male with $100 \%$ and the age was between 25-35 with $48.6 \%$ and 36- 45 and more with $50 \%$., It's obvious that the third question aims to know which type of frying oils would be the most common used between these types which answered to sunflower, corn , palm , mixed oils and shortening.

Then, we seek to know the reasons of using the most common frying oils in this question which answered to price, oil smell, flavor and other reasons. -it's clear that most restaurant use shortening more than any other oil with $77.1 \%$ for its price with $67.1 \%$ and for its flavor with $25.7 \%$.

There were different durations when we asked about how many hours they perform frying which answered to 4-6 hours , 6-8 hours , 8-10 hours , 1012 hours and 12-14 hours.

We need to know what do they do with the remaining oil if they add materials for oil to prolong the period of use or putting it away and using new one or other ways and we had to know in this question how often they change the frying oils ( every day - every two days - every week or other duration .

I think that we have to know what they do with their waste frying oils if they pour into the wastewater pipe or collect and dispose it into trash or collect it and sell to a buyer or there is other usage .

They mostly perform frying for 8-10 hours and 10-12 hours daily. they usually dispose the remaining oil as the end of the day and refill their fryer in the next day.

It's interesting that in question five the change frying oil every day with $75.7 \%$ but answers in question six indicate that $64.7 \%$ collecting the waste and selling it to buyer .

we have discussed here the methods of cleaning their fryers if they use hot water and soap or spray cleaner or other ways. Most restaurants clean their fryers with hot water and soap and don't perform any treatment to extend usage life of the frying oils with $77.1 \%$.

There was a need here to know if they perform any treatment to extend the usage life of their frying oils or they don't and in this next question we have discovered if they have any knowledge about codex regulations for frying oils or they don't have any information about it.

Finally in the last question we had to ask them about the problems which they face generally in the stages of their use of frying oils in the restaurant and the choices were ( high prices - product quality - lack of stability of oils used in frying process or there were any problems .

Then ,around $87.1 \%$ of them have indicated that they are not beware of the food codex regulations for frying oils, they have indicated too that most of the problems that they face in general in the stages of your frying oils in the restaurants are high prices with $70 \%$ and lack of stability of oils used in frying process with $21.4 \%$. 
Table(7) Statistical results of questionnaire which has been performed on the customers :

\begin{tabular}{|l|c|c|c|}
\hline $\begin{array}{l}\text { Question } \\
\text { number }\end{array}$ & Selections & Frequency & Percent \\
\hline Q1 & a & 46 & $50 \%$ \\
\hline \multirow{4}{*}{ Q2 } & b & 46 & $50 \%$ \\
\hline & a & 4 & $4.3 \%$ \\
& b & 12 & $13 \%$ \\
Q3 & c & 42 & $45.7 \%$ \\
& d & 34 & $37 \%$ \\
\hline \multirow{3}{*}{ Q4 } & a & 38 & $41.3 \%$ \\
& b & 22 & $23.9 \%$ \\
\hline \multirow{2}{*}{ Q5 } & c & 32 & $34.8 \%$ \\
\hline \multirow{3}{*}{ Q6 } & a & 39 & $42.4 \%$ \\
& b & 24 & $26.1 \%$ \\
\hline \multirow{2}{*}{ Q7 } & c & 29 & $31.5 \%$ \\
\hline & a & 36 & $39.6 \%$ \\
Q8 & c & 31 & $34.1 \%$ \\
& a & 24 & $26.4 \%$ \\
\hline
\end{tabular}

A questionnaire composed of 8 questions has been applied to 92 persons and their responses (\%) for each selection.

At the first, we have to know which type of gender they eat fried products more than the other and we have found that they are equal with 46 $\%$ for males and $46 \%$ for females .

It's clear that the second question asks about the age of the customers who eat in fast food restaurants which answered to $45.7 \%$ were from 20 to 30 years and 30 to 40 and more with $37 \%$.

Our third question asks about if the customer eat always fried food and its yes answers was $41.3 \%$ and no was with $23.9 \%$ and sometimes was 34.8 $\%$

Then we have to know if there is stability in the taste of fried product that the customers eat in the restaurant and the result was $42.4 \%$ with yes and $26.1 \%$ with no and $31.5 \%$ with sometimes.

On the other side we have to know if there is stability in the color of the fried products that he or she eats and we have found that $39.6 \%$ said that yes but $34.1 \%$ said no and on the other side 26.4 said sometimes there is stability in the color. 
We had to ask the customers if they think that the number of hours of frying affect on the quality of the fried product and it was $50 \%$ of them don't know if it affects or not and $30.4 \%$ the said yes it affects.

we have asked the customers too if they know that the oil is being reused many times, would they have the meal . the said no with $82.6 \%$ and $17.4 \%$ with yes .

Finally, we have to know what are the flaws that the customers have seen before in fried food from their point of view and we have found the biggest flaw was changing the taste with $52.2 \%$ then changing the color with $31.5 \%$ then $16.3 \%$ was for the changing of the smell.

\section{REFERENCES}

A.O.A.C. (2000)."Association of Official Analytical Chemists. OfficialMethods of Analysis.17th Ed.vol (11) Washington DC.USA.

Anon(2000) (fast food concepts), Anonymous sited from www.wikbedia.com.

Chavan, J. K.; Salumkhe, D. K. and Adsule, R. N. (1992)."World Oil Seeds, Chemistry, Technology and Utilization". Ch.3:59-95.

Chen,W.;Chiu,C.P.; Cheng,W.C.; Kai,C. and Kuo,M. (2013)." TotalPolar Compounds and Acid Value of Repeatedly Used FryingOils Measured by Standard and Rapid Methods". Journal ofFood and Drug Analysis. (21) $1: 58-65$.

Chowdhury, K.; Banu, L.A. Khan, S. and Lalif, A. (2007)."Studies onthe Fatty Acid Composition of Edible Oils". Bangladesh J. Sci. Ind. Res. 42(3):311-316.

Cizkova, H. ,Janota V., Voldrich M., Snebergo V. and Ales R., (2011) Survey study of frying oils used by food services in the Czech republic , food research institute, Bratislava .

Yılmaz, Emin, BuketAydeniz ( 2011) ÇanakkaleOnsekiz Mart University, Faculty of Engineering and Architecture Department of Food Engineering, Çanakkale, Turkey.

lqbal, S.; Haleem, S.; Akhtar, M.; Ul-Haq, M. and Akbar, J.(2008)."Efficiency of Pomegranate Peel Extracts in Stabilization of Sunflower Oil under Accelerated Conditions". Food Research International 41:194-200.

Talwar, Jennifer (2003), Fast Food, Fast Track, fast food concepts 12: 43 .

Martin,C.A.; Milinsk, M.C.; Visentainer, J.V.; Matsushita, M.andDe-Souza, N.E.(2007)."Trans fatty acid-forming processesIn food". Annals of the Brazilian Academy of sciences 79 (2):343-350.

Podmore,J.(2008)."Food applications of trans fatty acids". In AJDijkstra, RJ Hamilton and W Hamm (Eds.). (2008).Trans FattyAcids . Oxford : Blackwell Publishing .pp.202-218.

Radwan,SS(1978)."Coupling of two dimensional thin layerchromatography with GC for the quantitative analysis oflipid classes and their constituents fatty acids". J. chrom.Science 16:538-542.

Spss(20). program, statistical analysis program version (20). 


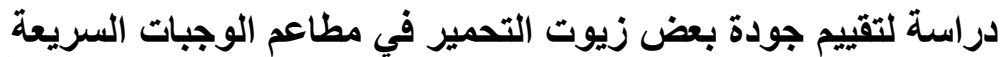

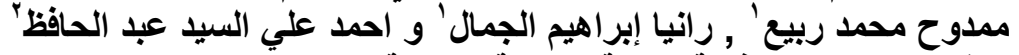

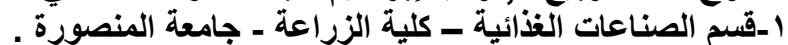

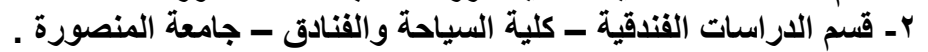

يهدف هذا البحث إلى دراسـة وتقيميم بعض أنواع زيوت القلي التي تم تجميعها بطريقهـ

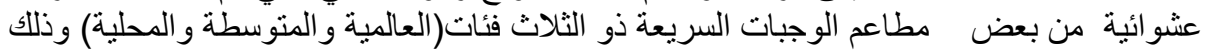

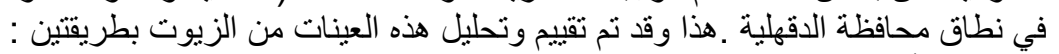

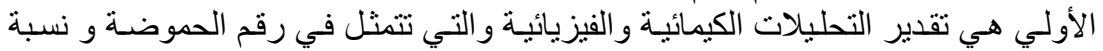

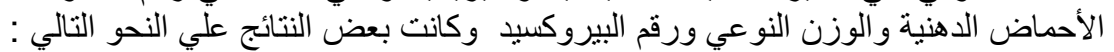

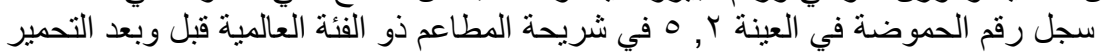

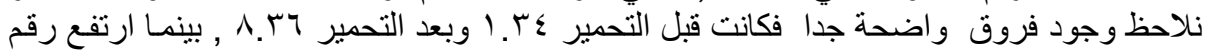

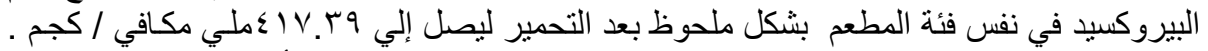

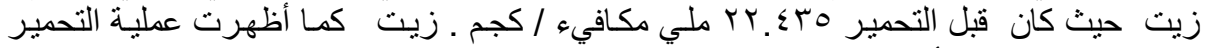

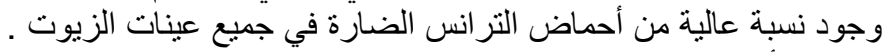

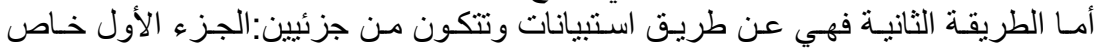

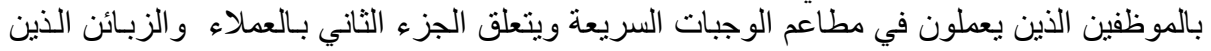

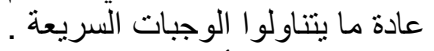

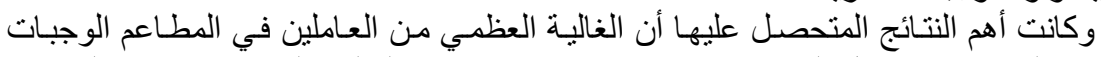

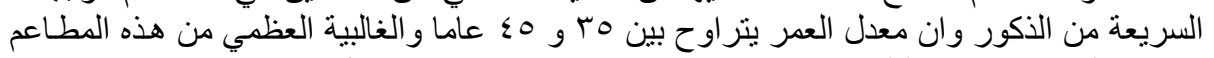

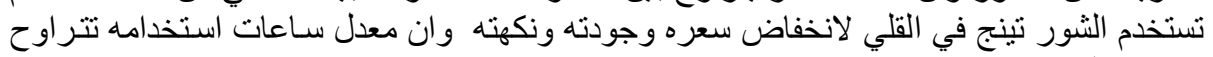

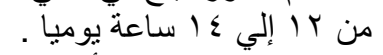

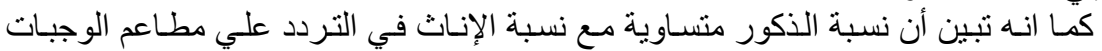

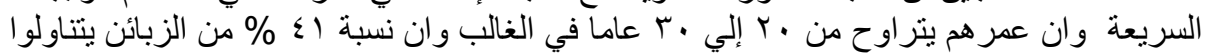

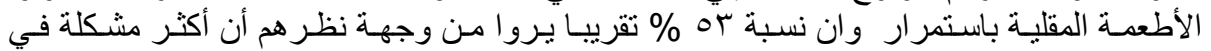

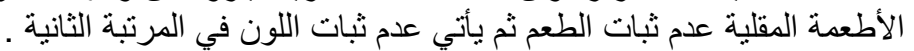

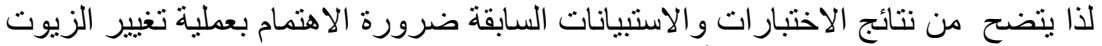

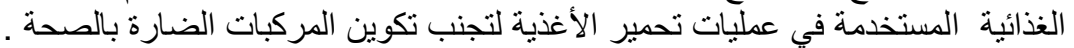

